Brazilian Journal
of Chemical
Engineering

\title{
SUNFLOWER OIL BLEACHING BY ADSORPTION ONTO ACID-ACTIVATED BENTONITE
}

\author{
E. L. Foletto ${ }^{1 *}$, G. C. Colazzo ${ }^{1}$, C. Volzone ${ }^{2}$ and L. M. Porto ${ }^{3}$ \\ ${ }^{1}$ Department of Chemical Engineering, Federal University of Santa Maria (UFSM), \\ 88040-900, Santa Maria - RS, Brazil. \\ E-mail: efoletto@gmail.com \\ ${ }^{2}$ Center of Technology of Mineral Resources and Ceramic, CETMIC (CIC-CONICET), \\ C.C. 49, (1897) M. B. Gonnet, Prov. Buenos Aires, Argentina. \\ ${ }^{3}$ Department of Chemical and Food Engineering, Federal University of Santa Catarina (UFSC), \\ P.O. Box 476, 88040-900, Florianópolis - SC, Brazil.
}

(Submitted: March 26, 2010 ; Revised: May 4, 2010 ; Accepted: August 31, 2010)

\begin{abstract}
Two bentonite clays with different mineralogical compositions from Mendoza, Argentine, were activated with $\mathrm{H}_{2} \mathrm{SO}_{4}$ solutions of 4 and $8 \mathrm{~N}$ at $90^{\circ} \mathrm{C}$ for 3.5 hours. This treatment affected clay structural properties, as was shown by thermogravimetry, infrared spectrometry and chemical analysis. Bleaching efficiency for sunflower oil was strongly dependent on the acid concentration used for clay activation. The samples have bleaching capacity comparable to that observed with a commercial adsorbent standard. The mineralogical composition of natural clays influenced the properties of the activated clays.

Keywords: Acid-treated clays; Bentonite; Oil bleaching; Sunflower oil.
\end{abstract}

\section{INTRODUCTION}

Acid activated bentonites have been used as solid acid catalysts and catalyst supports for a number of organic applications that require an extreme degree of reaction control of considerable industrial interest (Mokaya and Jones, 1995, Breen et al., 1997, Volzone et al., 2001, Foletto et al., 2002, Didi et al., 2009). They have also been used in the foodstuffs industry, for sulphur production, forest and water conservation, in the chemical industry, for environmental protection, and in the paper industry (Clarke, 1985, O'Driscoll, 1988), as well as for bleaching of vegetable oils (Srasra et al., 1989, Christidis et al., 1997, Foletto et al., 2003, Kirali and Laçin, 2006). The bleaching of edible vegetable oils involves the removal of a variety of impurities, which include phosphatides, fatty acids, gums, trace metals, etc., followed by decolorization. The bleaching capacity of bentonites is greatly increased by activation treatment. While some of these clays are naturally bleaching, some have to be treated with mineral acids (Grim, 1962; Patterson, 1992; Norris, 1982; Rossi et al., 2003; Rožić et al., 2010). Bentonite consists predominately of smectite, a 2:1 clay mineral containing an octahedral sheet between two tetrahedral sheets. Smectite crystals are negatively charged due to the substitution of the trivalent aluminium ions by divalent ions like $\mathrm{Mg}^{2+}$ and $\mathrm{Fe}^{+}$and substitution of tetrahedral $\mathrm{Si}^{4+}$ by $\mathrm{Al}^{3+}$ (Kirali and Laçin, 2006). Activation proceeds with partial dissolution of smectite and includes an initial replacement of the interlayer cations by $\mathrm{H}^{+}$, followed by dissolution of the octahedral and tetrahedral sheets, with subsequent release of structural cations. This attack alters the structure, chemical composition and physical properties of the clay while increasing the adsorption capacity (Mokaya et al., 1993). Christidis et al. (1997) examined the bleaching capacity and acid activation of bentonites from Aegean, Greece, observing a five-fold increase of the surface area of raw materials. The activated samples

*To whom correspondence should be addressed 
were rendered suitable for bleaching of rapeseed oil. It was determined that the optimum bleaching capacity in not associated with maximum surface area and the optimum conditions for activation are obtained by using a variety of combinations of acid strength and residence time. Despite numerous studies, no definite relationship exists between the performance of the acid-activated clay and the composition or properties of the original clay. Hence, each clay has to be specifically activated and tested for its performance (Hymore, 1996). The preparation of acid-activated bentonite must be controlled in order to obtain maximum bleaching capacity (Kirali and Laçin, 2006, Rožić et al., 2010).

The present study deals with the acid activation of Argentine bentonites and testing of their bleaching capacity for sunflower oil, in comparison with the bleaching capacity of a standard commercial bleaching clay.

\section{EXPERIMENTAL}

Two natural bentonites (named $\mathrm{K}$ and $\mathrm{W}$ ) from two different deposits of the Mendoza province, Argentine, were used as the starting materials. Tonsil, a commercial acid-activated bentonite extensively used in the vegetable oil industry, was used as reference for the evaluation of the bleaching capacity in the experiments. Alkali-refined sunflower oil was gently donated by Bunge Alimentos S.A (Gaspar-SC, Brazil).

The bentonite sample $(40 \mathrm{~g})$ was treated with 400 $\mathrm{mL}$ of $4 \mathrm{~N}$ or $8 \mathrm{~N}$ sulphuric acid (analytical grade) at $90^{\circ} \mathrm{C}$ for $3.5 \mathrm{~h}$ (Foletto et al., 2003) in a stirred glass reaction vessel with reflux. After the acid treatment, the sample was filtered and washed with distilled water until free of $\mathrm{SO}_{4}{ }^{2-}$. The samples were dried at $60^{\circ} \mathrm{C}$ for $12 \mathrm{~h}$ and ground to pass through a 0.074 $\mathrm{mm}$ sieve. Activated samples were designated as $\mathrm{K} 4$, $\mathrm{K} 8$, W4 and $\mathrm{W} 8$, where the numerical value indicates the concentration of acid solution used for the treatment. Bleaching experiments were conducted by a procedure analogous to that of the American oil Chemical Society (AOCS) Official Method Cc 8a-52. The bleaching process was carried out under a vacuum of $450 \mathrm{mmHg}$ at the constant temperature of $100^{\circ} \mathrm{C}$ with a contact time of $30 \mathrm{~min}$. Stirring and heating were carried out by means of a mechanical stirrer and an electric heating band. The ratio of the mass of clay to the volume of acid solution was $1: 10(\mathrm{w} / \mathrm{v})$. During the bleaching, a stream of $\mathrm{N}_{2}$ was maintained above the oil surface. The hot oil and clay mixture was filtered under vacuum and the color of the bleached oil was measured spectrophotometrically (WFJ525-W UVvisible spectrophotometer). The bleaching capacity percentage of the clays was determined from the equation (Falaras et al., 1999):

$\mathrm{BC}(\%)=\left[\left(\mathrm{A}_{0}-\mathrm{A}\right) / \mathrm{A}_{0}\right] \times 100$

where " $\mathrm{A}_{0}$ " and " $\mathrm{A}$ " are the absorbance of neutral oil and bleached oil, respectively, at the maximum absorbance wavelength of the neutral oil $(420 \mathrm{~nm})$. The structural changes of the Argentinean acid bentonites were examined by means of thermogravimetric (TGA) and infrared spectrometric (IR) analyses and chemical analysis (XRF). TGA was performed with a Netzsch STA 409 thermal analyzer at a heating rate of $10^{\circ} \mathrm{C} \cdot \mathrm{min}^{-1}$ under a flow of atmospheric air of $35 \mathrm{~mL} \mathrm{~min}^{-1}$, in the temperature range $25-1000^{\circ} \mathrm{C}$. IR spectra were recorded in the region $4000-350 \mathrm{~cm}^{-1}$ with a Perkin-Elmer 16 PC spectrophotometer, using the $\mathrm{KBr}$ pellet technique. Chemical compositions of the samples were determined by X-ray fluorescence with a Philips PW 2400 spectrometer.

\section{RESULTS AND DISCUSSION}

The mineralogical compositions of two clay samples were determined by Foletto et al. (2000). Smectite is the main clay mineral in both samples (35\% in $\mathrm{K}$ and $47 \%$ in $\mathrm{W}$ ). The $\mathrm{K}$ bentonite contains quartz and feldspar as impurities, whereas W bentonite contains also gypsum and kaolinite. Table 1 shows the chemical analysis of the bentonites after treatment with sulfuric acid. The interlayer cations of the bentonites were removed.

Table 1: Results of XRF analysis, expressed as oxides (\%).

\begin{tabular}{|c|c|c|c|c|c|c|c|c|c|c|}
\hline Sample & $\mathbf{S i O}_{\mathbf{2}}$ & $\mathbf{A l}_{\mathbf{2}} \mathbf{O}_{\mathbf{3}}$ & $\mathbf{F e}_{\mathbf{2}} \mathbf{O}_{\mathbf{3}}$ & $\mathbf{M g O}$ & $\mathbf{C a O}$ & $\mathbf{N a}_{\mathbf{2}} \mathbf{O}$ & $\mathbf{K}_{\mathbf{2}} \mathbf{O}$ & $\mathbf{T i O}_{\mathbf{2}}$ & $\mathbf{M n O}$ & ${ }^{*} \mathbf{r}$ \\
\hline $\mathrm{K}$ & 69.53 & 15.58 & 3.49 & 1.56 & 0.65 & 2.70 & 1.23 & 0.55 & 0.09 & 3.00 \\
$\mathrm{~K} 4$ & 77.45 & 12.55 & 2.03 & 1.02 & 0.35 & 0.85 & 1.10 & 0.55 & 0.01 & 4.35 \\
$\mathrm{~K} 8$ & 78.51 & 10.32 & 1.59 & 0.85 & 0.32 & 0.88 & 1.04 & 0.54 & 0.01 \\
$\mathrm{~W}$ & 65.18 & 17.51 & 4.53 & 1.18 & 1.57 & 2.24 & 0.86 & 0.42 & 0.08 & 2.37 \\
$\mathrm{~W} 4$ & 73.08 & 14.70 & 3.43 & 0.64 & 0.18 & 0.57 & 0.71 & 0.42 & 0.01 & 3.50 \\
$\mathrm{~W} 8$ & 75.87 & 13.06 & 2.86 & 0.59 & 0.18 & 0.59 & 0.71 & 0.42 & 0.01 & 4.12 \\
\hline
\end{tabular}

* r: $\mathrm{Si}^{4+} /\left(\mathrm{Al}^{3+}+\mathrm{Mg}^{2+}+\mathrm{Fe}^{2+/ 3+}\right)$ ratio. 
The residual $\mathrm{Ca}^{2+}, \mathrm{Na}^{+}$and $\mathrm{K}^{+}$are due to the presence of impurities such as micas and feldspars, which are insoluble in acid medium (Barrios et al., 1995). Part of the $\mathrm{Mg}^{2+}, \mathrm{Fe}^{2+/ 3+}$ and $\mathrm{Al}^{3+}$ was removed from the octahedral sheet. $\mathrm{Ti}^{4+}$ cations were insoluble. The increase of $\mathrm{Si}^{4+}$ and the reduction of the octahedral cations, with the increase of the acid concentration resulted in an increase of the $\mathrm{Si} /(\mathrm{Al}+\mathrm{Mg}+\mathrm{Fe})$ ratio. The loss of weight due to dehydroxylation (\%) of the samples, obtained from TGA curves, occurred in the range $450-750^{\circ} \mathrm{C}$ (Figure 1); the TGA curves were used for the evaluation of the extent of the attack of the acid treatment on the octahedral sheets (Table 2). The octahedral sheet destruction was calculated as a relative percentage reduction of the weight loss, with respect to the original sample (Foletto et al., 2003). The activated $\mathrm{K}$ samples showed 14 to $19 \%$ destruction of the octahedral sheet, while the activated $\mathrm{W}$ samples showed
12 to $15 \%$ destruction. These results showed that, even at high acid concentration (i.e., a concentration of $8 \mathrm{~N}$ ), the structure of smectites was not totally destroyed.

Figure 2 shows the infrared spectra of the original and the acid-treated bentonites. No important changes were observed, although the Si-O-Al $\left(525 \mathrm{~cm}^{-1}\right)$ and Si-O-Si $\left(465 \mathrm{~cm}^{-1}\right)$ bands were modified. The intensity ratios of both bands are shown in Table 3. Table 3 presents the results of the characterizations of the natural and activated samples and for bleaching of sunflower oil. Figures 3, 4 and 5 show the relation between the structural changes and bleaching capacity of the bentonites. The results of the analyses indicate that an increase of the acid concentration causes a greater attack on the bentonite structure and, consequently, improves the bleaching capacity. The level of clay attack was higher for the $\mathrm{K}$ that the $\mathrm{W}$ sample.

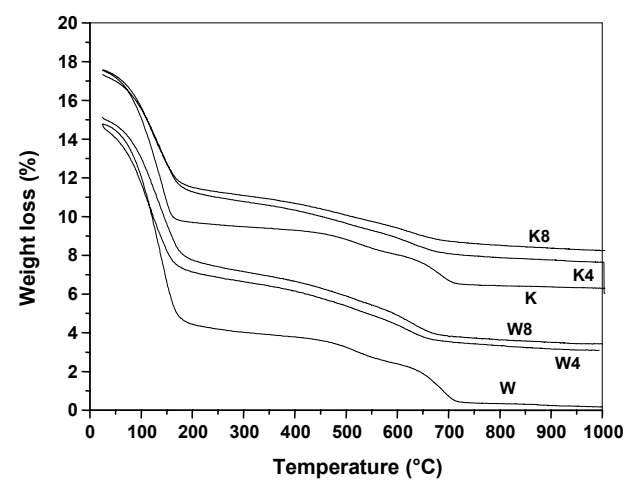

Figure 1: TGA curves of the natural and activated samples.

Table 2: Results obtained from TGA curves.

\begin{tabular}{|c|c|c|}
\hline Sample & Weight loss (\%) range $\mathbf{4 5 0}-\mathbf{7 5 0} \mathbf{~} \mathbf{C}^{\mathbf{C}}$ & Octahedral sheet destruction (\%) \\
\hline K & 2.69 & 22.60 \\
K4 & 2.08 & 33.08 \\
K8 & 1.80 & 0.00 \\
W & 3.28 & 21.04 \\
W4 & 2.59 & 25.61 \\
\hline
\end{tabular}

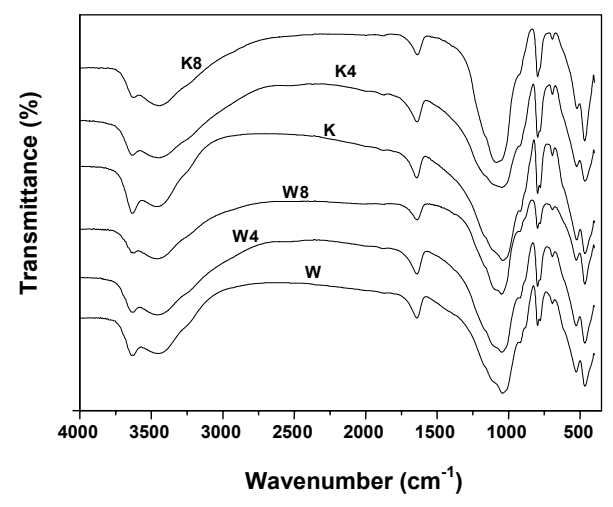

Figure 2: Infrared spectra of natural and activated samples. 
Table 3: Structural changes and oil bleaching capacity of natural and activated samples.

\begin{tabular}{|c|c|c|c|c|}
\hline Sample & IR $^{(\mathbf{1})}$ & $\mathbf{C A}^{(\mathbf{2})}$ & TG $^{(\mathbf{3})}$ & $\begin{array}{c}\mathbf{B C}^{(\%)} \text { (\%) } \\
\text { Sunflower }^{\text {(4) }}\end{array}$ \\
\hline K & 0.44 & 3.00 & 0.00 & 11.83 \\
K4 & 0.26 & 4.35 & 22.67 & 39.74 \\
K8 & 0.13 & 5.37 & 33.08 & 48.68 \\
W & 0.44 & 2.56 & 0.00 & 11.00 \\
W4 & 0.34 & 3.50 & 21.04 & 35.20 \\
W8 & 0.22 & 4.12 & 25.61 & 45.60 \\
\hline
\end{tabular}

(1) $\mathrm{Si}-\mathrm{O}-\mathrm{Al} / \mathrm{Si}-\mathrm{O}-\mathrm{Si}$ ratio (obtained from IR spectra, Figure 2).

(2) $\mathrm{Si} /(\mathrm{Al}+\mathrm{Mg}+\mathrm{Fe})$ ratio (obtained from chemical analysis, Table 1).

(3) Octahedral sheet destruction (\%) (obtained from TGA curves, Table 2).

(4) Bleaching capacity

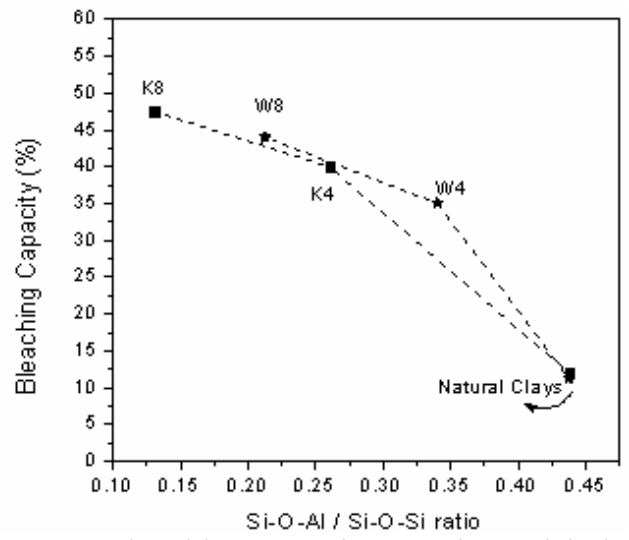

Figure 3: Bleaching capacity $v s$. Si-O-Al / Si-O-Si ratio.

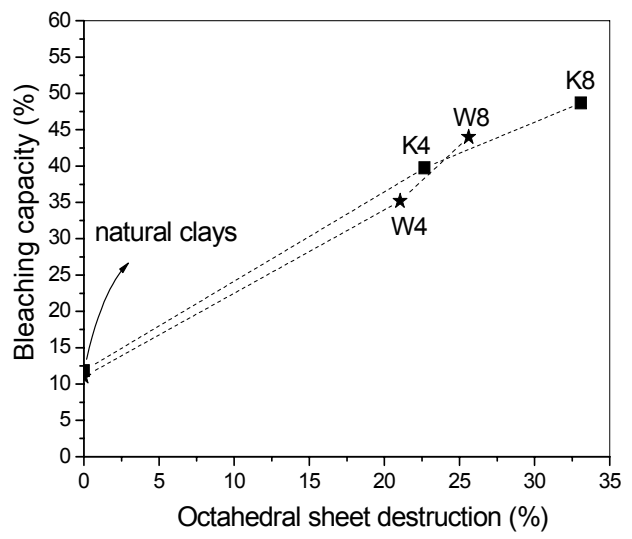

Figure 4: Bleaching capacity $v$ s. octahedral sheet destruction.

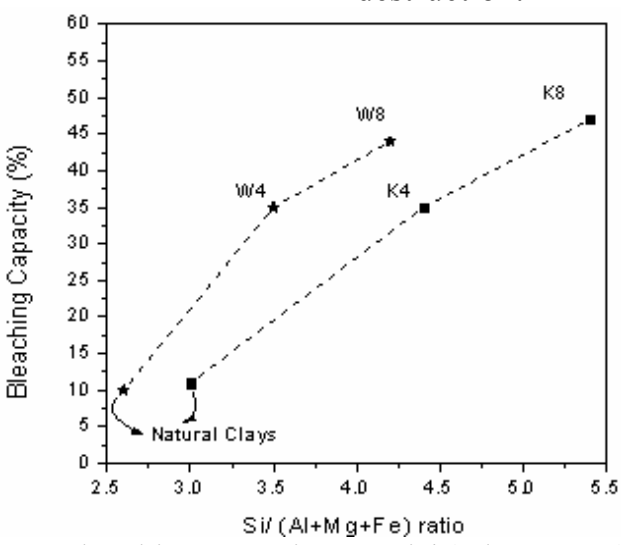

Figure 5: Bleaching capacity $v s . \mathrm{Si} /(\mathrm{Al}+\mathrm{Mg}+\mathrm{Fe})$ ratio.

The acid activated $\mathrm{K}$ bentonites showed a slightly superior bleaching capacity than the acid W bentonites and this behavior could be attributed to the greater effect of the acid attack on the K smectite structure when compared to the $\mathrm{W}$ smectite. Comparing the mineralogical compositions, the sample $\mathrm{K}$ presents a higher $\mathrm{MgO}$ content than sample W. It has been observed that smectites with greater $\mathrm{MgO}$ contents in their structure are more activated by mineral acids than those smectites with minor $\mathrm{MgO}$ content (Volzone and Ortiga, 2000). An optimization of the experimental conditions of acid treatment of the $\mathrm{W}$ bentonite would probably cause a higher attack on its structure and, consequently, would lead to a better adsorptive capacity, because this sample has a higher clay content than $\mathrm{K}$ bentonite (Foletto et al., 2000).

The best bleaching capacity $(\mathrm{BC})$ results of the activated bentonites obtained in this work were compared with a commercial sample, as shown in 
Table 4. The retention of colored impurities of sunflower oil by Tonsil (commercial sample) was similar to those of the bentonites treated with $8 \mathrm{~N}$ sulphuric acid.

Table 4: Bleaching capacities (BC) of Tonsil and the acid-treated bentonites (K8 and W8).

\begin{tabular}{|l|c|}
\hline Sample & BC (\%) Sunflower \\
\hline Tonsil & 48.57 \\
K8 & 48.68 \\
W8 & 45.60 \\
\hline
\end{tabular}

\section{CONCLUSION}

Attack on the bentonite structure as a result of sulfuric acid treatment is strongly dependent on the acid concentration. The effects of these treatments on clay structural properties were determined by thermogravimetric, infrared spectrometric analysis and chemical analysis. The activated samples were tested in order to verify their bleaching capacity for sunflower oil and were compared to a standard commercial bleaching clay. Bleaching efficiency was strongly dependent on the acid concentration used for clay activation. The treated samples showed a bleaching capacity comparable to the standard. The mineralogical composition of natural clays influenced the properties of the treated clays and these properties increased its bleaching power.

\section{ACKNOWLEDGMENTS}

Financial support of CAPES and CNPq, Brazilian governmental agencies for education and research, and PIP02100-CONICET, Argentina are thankfully acknowledged.

\section{REFERENCES}

Barrios, M. S., Gonzáles, L. V. F., Rodríguez, M. A. V. and Pozas, J. M. M., Activation of a palygoskite with $\mathrm{HCl}$ : development of physicochemical, textural and surface properties. Applied Clay Science, 10, 247-258 (1995).

Breen, C., Zahoor, F. D., Madejová, J. and Komadel, $\mathrm{P}$., Characterization and catalytic activity of acidtreated, size-fractionated smectites. Journal of Physical Chemistry B, 27, 5324-5331 (1997).

Christidis, G. E., Scott, P. W. and Dunham, A. C., Acid activation and bleaching capacity of bentonites from the Islands of Milos and Chios, Aegean, Greece. Applied Clay Science, 12, 329347 (1997).

Clarke, G. M., Special clays. Industrial Minerals, 216, 25-51 (1985).

Didi, M. A., Makhoukhi, B., Azzouz, A. and Villemin, D., Colza oil bleaching through optimized acid activation of bentonite. A comparative study, Applied Clay Science, 42, 336-344 (2009).

Falaras P., Kovais, I., Lezou, F. and Seiragakis, G., Cottonseed oil bleaching by acid-activated montmorillonite. Clay Minerals, 34, 221-232 (1999).

Foletto, E. L., Valentini, A., Probst, L. F. D. and Porto, L. M., Gas-phase $\beta$-pinene isomerization over acid-activated bentonite. Latin American Applied Research, 32, 141-144 (2002).

Foletto, E. L., Volzone, C., Morgado, A. F. and Porto, L. M., Análise comparativa da ativação ácida de dois materiais argilosos com diferentes composições mineralógicas. In: VI Jornadas Argentinas de Tratamiento de Minerales, Salta (Argentina) 43-48 (2000). (In portuguese).

Foletto, E. L., Volzone, C. and Porto, L. M., Performance of an Argentinian acid-activated bentonite in the bleaching of soybean oil. Brazilian Journal of Chemical Engineering, 20, 139-145 (2003).

Grim, R. E., Applied Clay Mineralogy, McGraw Hill, New York, pp. 442 (1962).

Hymore, F. K., Effects of some additives on the performance of acid-activated clays in the bleaching of palm oil. Applied Clay Science, 10, 379-385 (1996).

Kirali, E. G. and Laçin, O., Statistical modelling of acid activation on cotton oil bleaching by Turkish bentonite, Journal of Food Engineering, 75, 137141 (2006).

Mokaya, R. and Jones, W., Pillared clays and pillared acid-activated clays: a comparative study of physical, acidic and catalytic properties. Journal of Catalysis, 153, 76-85 (1995).

Mokaya, R., Jones, W., Davies, M. E. and Whittle, M. E., Chlorophyll adsorption by alumina pillared acid-activated clay. Journal of the American Oil Chemists' Society, 70, 241-244 (1993).

Norris, F. A., Extraction of fats and oils. In: Bailey's Industrial Oil and Fat Products, 2nd ed., New York: Daniel Swern (ed.), John Wiley \& Sons, 175-251 (1982).

O'Driscoll, M., Bentonite: overcapacity in need of markets. Industrial Minerals, 250, 43-67 (1988). 
Patterson, H. B. W., Bleaching and Purifying fats and oils: theory and practice. AOCS Press, Champaign, Ilinois, USA, pp. 242 (1992).

Rossi, M., Gianazza, M., Alamprese, C. and Stanga, F., The role of bleaching clays and synthetic silica in palm oil physical refining, Food Chemistry, 82, 291-296 (2003).

Rožić, L., Novaković, T., and Petrović, S., Applied Clay Science, Modeling and optimization process parameters of acid activation of bentonite by response surface methodology, 48, 154-158 (2010).

Srasra, F., Bergaya, H., van Damme, H. and Ariguib,
N. K., Surface properties of an activated bentonite - Decolorisation of rape-seed oils. Applied Clay Science, 4, 411-421 (1989).

Volzone, C., Masini O., Comelli, N. A., Grzona, L. M., Ponzi, E. N. and Ponzi M. I., Production of camphene and limonene from pinene over acid di- and trioctahedral smectite clays. Applied Catalysis A: General, 2, 213-218 (2001).

Volzone, C. and Ortiga, J., $\mathrm{O}_{2}, \mathrm{CH}_{4}$ and $\mathrm{CO}_{2}$ gas retentions by acid smectites before and after thermal treatment. Journal of Materials Science, 35, 5291-5294 (2000). 